\title{
PENGEMBANGAN TEMA PEMBELAJARAN UNTUK TAMAN KANAK-KANAK
}

\author{
Ika Budi Maryatun, PAUD FIP UNY \\ ika_budimaryatun@uny.ac.id
}

\begin{abstract}
Abstrak
Artikel ini bertujuan untuk menjabarkan langkah-langkah pengembangan tema pembelajaran di Taman Kanak-kanak. Metode penelitian yang digunakan adalah kajian literasi untuk menggali berbagai teori tentang pengembangan tema. Hasil dari kajian adalah langkah pengembangan tema yang meliputi tiga langkah utama, yaitu persiapan, pelaksanaan, dan tindak lanjut. Langkah persiapan berisi analisis sumber tema. Langkah pelaksanaan meliputi : (1) memilih topik sebagai tema; (2) brainstorming tentang tema; (3) mencari literatur; (4) mengembangkan tema besar menjadi tema kecil; (5) menyusun konsep pengetahuan; (6) menentukan puncak tema; dan (7) melaksanakan tema. Langkah tindak lanjut berisi evaluasi pelaksanaan tema.
\end{abstract}

Kata kunci: Tema pembelajaran, taman kanak-kanak

\section{DEVELOPING LEARNING THEMES FOR KINDERGARTEN}

\begin{abstract}
This article aims to outline the steps of developing the theme of learning in Kindergarten. The research method used is literacy study to explore various theories about theme development. The result of the study is the theme development step which includes three main steps, namely preparation, implementation, and assessment as follow-up. The preparation step contains the theme's source analysis. Implementation steps include: (1) choosing a topic as theme; (2) brainstorming on themes; (3) searching the literature; (4) developing big themes into small themes; (5) construct the concept of knowledge; (6) determine the top of the theme; and (7) carrying out the theme. The follow-up step contains an evaluation of the implementation of the theme.
\end{abstract}

Keywords: theme, learning, kindergarten

\section{PENDAHULUAN}

Kurikulum 2013 memiliki ciri khusus dalam pelaksanaannya, yaitu pembelajaran saintifik dan tematik (Permendikbud No. 146 tahun 2014). Pembelajaran tematik diatur dalam kurikulum 2013 PAUD karena pembelajaran tematik dipandang sesuai dengan pola kerja otak anak usia dini. Pembelajaran temati membahas satu tema dari berbagai konsep dan aspek perkembangan secara tuntas. Kurikulum 2013 PAUD juga tidak kaku dalam mengatur pemilihan dan pelaksanaan tema pembelajaran di PAUD, termasuk Taman Kanak-kanak (TK).

Tema merupakan topik atau konsep yang luas bagi anak, seperti diri sendiri, lingkungan, teman, ataupun musim (Jackman, 2009). Tema disebut juga sebagai topik penyatu ataupun jembatan penghubung seluruh kegiatan dalam satu hari (Yuliani Nurani 2013). Tema di Taman Kanak-kanak dalam kurikulum 2010 dan sebelumnya dimuat secara baku sebanyak 11 tema. Tema-tema tersebut juga telah diatur lama pembahasannya sehingga terjadi keseragaman di seluruh Indonesia.

Tema pembelajaran dalam kurikulum sebelumnya diatur dalam kurikulum yang membuat pelaksanaan pembelajaran di seluruh Indonesia membahas topik yang sama. Hal ini bertentangan dengan kondisi Indonesia yang kondisi sosial dan budayanya beragam. Penyeragaman topik 
ini mengakibatkan pembelajaran menjadi kurang bermakna bagi anak usia TK. Anak terpaksa membahas sesuatu yang jauh dari kehidupan nyatanya. Sebagai contoh, anak di pesisir harus membahas kehidupan di perkotaan, dan sebaliknya. Kurikulum 2013 memberi keleluasaan lembaga sekolah untuk dapat mengembangkan tema pembelajaran yang sesuai dengan kondisi sekolah (sosialisasi kurikulum 2013, 2014). Sekolah dituntut kreatif mengembangkan tema agar pembelajaran sesuai dengan kondisi nyata anak sehingga pembelajaran menjadi lebih bermakna. Tema juga sebaiknya dikembangkan oleh masingmasing sekolah agar sesuai dengan karateristik sekolah yang bersangkutan.

Hasil penelitian awal penulis memperoleh data bahwa dari 70 guru Taman Kanak-kanak, hanya 6 orang guru atau 8,5 persen guru pernah mengembangkan tema di luar tema yang sudah ditentukan dinas dalam pembelajaran. Adapun 64 guru TK yang lain mengembangkan tema sesuai dengan tema contoh di kurikulum terdahulu yaitu tema Diri Sendiri, Lingkunganku, Kebutuhan, Tanaman, Binatang, Alat Komunikasi, Pekerjaan, Rekreasi, Air, Udara, Api, Negaraku, Alam Semesta. Data ini berarti 91,5 persen guru belum mengembangkan pembelajaran anak di kelasnya berdasarkan kondisi sekolah (Maryatun dkk, 2016).

Beberapa alasan guru tidak mengembangkan sendiri tema pembelajaran di kelasnya adalah 1) kurangnya pengetahuan guru untuk mengembangkan tema, 2) tidak adanya pelatihan khusus yang dapat diikuti untuk mengembangkan tema, 3) guru kesulitan dalam mengembangkan tema untuk anakanak karena terbatasnya biaya dan peralatan sumber belajar yang mendukung, dan 5) kesulitan dalam mengembangkan rencana pembelajaran untuk anak dalam bentuk rancangan harian (Maryatun dkk, 2016).

Kemampuan dan keterampilan mengembangkan tema mutlak diperlukan oleh guru agar pembelajaran menjadi bermakna. Karenanya dibutuhkan bahan bacaan untuk acuan dalam mengembangkan tema pembelajaran di Taman Kanak-kanak. Artikel ini menjabarkan berbagai langkah yang harus dilakukan pendidik untuk mengembangkan tema. Artikel ini dapat digunakan pendidik sebagai acuan awal dalam mengembangkan tema pembelajaran, khususnya di TK.

\section{Tema Pembelajaran}

Tema di dalam kegiatan pembelajaran untuk anak usia dini merupakan alat atau wadah untuk mengenalkan konsep kepada anak didik secara utuh (Montolalu dkk., 2012, 11.10). Tema digunakan dalam pembelajaran untuk anak usia dini bertujuan membangun pengetahuan pada anak dan mengembangkan seluruh aspek perkembangan anak. Tema pada kegiatan pembelajaran ank usia dini bukan merupakan tujuan pembelajaran melainkan sebagai perluasan wawasan dalam rangka menghantarkan kematangan perkembangan anak. Pembelajaran menggunakan tema memiliki kekuatannya sendiri dibanding pembelajaran bidang studi. Kekuatan pembelajaran yang dirancang menggunakan tema, antara lain sebagai berikut (Nurani, 2013).

a. Pengalaman dan kegiatan belajar relevan dengan tingkat perkembangan dan kebutuhan anak.

b. Menyenangkan karena bertolak dari minat dan kebutuhan anak.

c. Hasil belajar akan bertahan lama karenalebih berkesan dan bermakna.

d. Mengembangkan keterampilan berfikir anak dengan permasalahan yang dihadapi.

e. Menumbuhkan keterapilan sosial dalam bekerjasama, toleransi, komunikasi, dan tanggap terhadap gagasan orang lain. 


\section{METODE PENELITIAN}

Artikel ini ditulis mengacu pada penelitian pengembangan panduan penyusunan tema pembelajaran di Taman Kanak-kanak pada tahap pengembangan draft. Artikel ini adalah hasil pengembangan draft yang akan dijadikan panduan pengembangan tema pembelajaran di TK. Penelitian awal yang dilakukan merupakan penelitian kajian literasi untuk menggali langkah pengembangan tema. Teknik pengumpulan data penelitian adalah dokumentasi, yaitu mengumpulkan berbagai referensi tentang pengembangan tema pembelajaran di TK. Hasil dokumentasi dalam artikel ini nantinya masih perlu divalidasi baik ahli maupun pengguna.

Pemilihan tema tidak sekedar mengambil topik yang diingat guru saja, melainkan perlu mempertimbangkan kebermanfaatannya. Tema yang dipilih adalah tema yang akan bermanfaat jika diterapkan sehingga pembelajaran yang dilaksanakan menjadi bermakna. Adapun pemilihan tema agar menjadi bermanfaat perlu mempertimbangkan hal-hal berikut (Essa, 2003).

a. Topik yang digunakan sebagai tema adalah hal-hal yang layak dibahas. Artinya topik perlu memperhatikan pengalaman anak maupun etika yang berlaku di masyarakat. Misalnya, membahas binatang lebih layak daripada membahas hantu.

b. Tema sebaiknya memfasilitasi tujuan dan standar negara. Misalnya tujuan pendidikan di Indonesia adalah menciptakan manusia Indonesia seutuhnya, maka sebaiknya tema yang dikembangkan adalah tema yang berbasis budaya. Tujuannya agar budaya sebagai identitas bangsa dapat dilestarikan.

c. Tema haruslah menarik dan relevan dengan dunia anak-anak. Suatu topik yang tidak menarik tidak akan mampu membawa anak ke dalam pembelajaran yang menyenangkan. d. Tema sebaiknya dipilih yang mampu memberikan kesempatan anak untuk berpraktik seluas-luasnya. Contoh, jika guru ingin menanamkan keterampilan menggunting, maka tema sebaiknya adalah pakaian.

Kebermanfaatan tema ini akan mempengaruhi kebermaknaan pembelajaran anak. Tema-tema yang dikembangkan sebaiknya dilaksanakan secara tuntas agar anak menguasai konsep tentang tema dengan baik yang nantinya akan dapat digunakan dalam kehidupan nyata anak-anak. Kebermanfaatan dan kebermaknaan pemilihan tema ini sebaiknya didukung dengan hal-hal yang perlu dihindari. Hal-hal yang perlu dihindari ketika memilih topik untuk dijadikan tema adalah topik tidak sesuai dengan kehidupan dan pengetahuan anak, misalnya tema padang pasir di sekolah Jakarta. Hal lain adalah topik sebagai tema yang tidak nyata, misalnya tema hantu.

\section{Taman Kanak-Kanak}

Taman-kanak (TK) sering juga disebut prasekolah, yaitu sekolah yang sesuai dengan karakteristik dan kebutuhan anak usia 4 - 6 tahun (Brewer, 2007). Peraturan pemerintah Indonesia mengatur TK sebagai layanan PAUD untuk anak usia 4-6 tahun (Permendikbud 146 tahun 2014 pasal 2 ayat 1). TK dibagi menjadi dua jenjang lagi, yaitu TK Kelompok A usia 45 tahun dan TK Kelompok B usia anak 5-6 tahun.

Anak dimasukkan ke lembaga pendidikan TK sesuai tujuan PAUD adalah bukan untuk mempersiapkan anak bisa calistung dan dapat masuk SD. Namun TK bertujuan untuk mengajak anak belajar sepanjang hayat seperti deklarasi Dakkar.

Pembelajaran di TK dilaksanakan menganut prinsip bermain, karena bermain bagi anak-anak adalah jntung kegiatan. Bermain memberikan kebebasan dan kesukarelaan pada anak untuk berekspresi, berkarya, maupun berkomunikasi pada anak. 


\section{HASIL PENELITIAN DAN PEMBAHASAN}

Hasil penelitian literasi memperoleh data tentang pengembangan tema yang diperlukan oleh pendidik. Secara umum pengembangan tema dibagi menjadi tiga tahap (Kostelnik, 2007).

Tahap persiapan pengembangan tema. Tahap ini meliputi berbagai persiapan yang perlu dilakukan guru sebelum mengembangkan tema adalah menganalisis sumber tema. Tema dapat berasal dari berbagai sumber (Caouglin, 1997). Sumber yang biasanya digunakan untuk menggali tema, yaitu : a) Anak. Anak merupakan sumber tema yang paling baik karena tema yang baik berbasis minat anak sehingga pembelajaran yang dilaksanakan benarbenar bermakna; b) kejadian istimewa merupakan sumber tema yang selanjutnya, seperti peringatan hari kemerdekaan; c) kejadian yang sedang berlangsung merupakan sumber tema yang insidental tetapi akan sangat menarik dan bermakna bagi anak, misalnya saat gunung kelud meletus, guru dapat mengangkat tema bencana gunung meletus ataupun tema debu; d) tema juga dapat berasal dari guru atau anggota keluarga.

Tahap pengembangan tema. Banyaknya sumber tema membuat pendidik terkadang kesulitan memilih tema mana yang sesuai untuk diterapkan di kelasnya. Pemilihan tema ini sebaiknya memperhatikan karakteristik tema yang ada agar sesuai dengan tujuan pengembangan tema itu sendiri (Brewer, 2007). Adapun karakteristik tersebut antara lain. (Jalongo \& Stamp, 1997 dalam Kostelnik, 2007; Brewer 2007) : 1) dibangun dari pengetahuan dan pengalaman nyata anak sehari-hari di lingkungannya; disesuaikan dengan usia dan budaya anak; 3) menyajikan konsep untuk digali oleh anak; 4) didukung oleh pengetahuan faktual hasil penelitian dan pengalaman guru selama mengajar; 5) mencakup pengalaman pertama dan langsung bagi anak; 6) meliputi 6 aspek perkembangan yang menggambarkan bidang kurikulum (bahasa, kognitif, fisik-motorik, NAM, sosial emosional, dan seni) serta mendukung keterpaduannya; 7) mencakup materi secara tematik yang dilakukan lebih dari sekali dan dalam berbagai aktivitas (bermain eksplorasi, penemuan terbimbing, problem solving, diskusi, demonstrasi, instruksi langsung dalam kelompok kecil maupun klasikal); 8) memadukan isi dan proses pembelajaran; 9) memberikan kesempatan pada anak untuk praktik dan menerapkan keterampilan dasar sesuai usianya; 10) memperluas topik yang berasal dari ide anak dan langsung untuk anak; 11) mendorong anak untuk mendokumentasikan dan merefleksikan apa yang dipelajarinya; 12) melibatkan keluarga anak dalam berbagai cara.

Tema-tema yang disusun juga perlu memenuhi kriteria sebagai berikut (Kostelnik, 2007; Feneey, et.al, 2006) :

a. Relevansi, bahwa tema yang disusun sebaiknya dibangun dari pengetahuan dan pengalaman nyata anak sehari-hari di lingkungannya.

b. Berkesinambungan, bahwa tema yang disusun sebaiknya mencakup materi yang dilakukan lebih dari sekali dan dalam berbagai aktivitas (bermain eksplorasi, penemuan terbimbing, problem solving, diskusi, demonstrasi, instruksi langsung dalam kelompok kecil maupun klasikal).

c. Keberagaman \& Keseimbangan lintas kurikulum, bahwa tema yang disusun perlu memuat seluruh aspek perkembangan kurikulum secara seimbang dan bervariasi.

d. Ketersediaan sumber dan materi pembelajaran, bahwa dalam menyusun tema sebaiknya memperhatikan kemudahan dalam mencari sumber dan materi pembelajaran di sekitar sekolah.

e. Berpotensi sebagai proyek, tema yang disusun merupakan topik yang dapat dikembangkan sebagai ide dan proyek dalam pembelajaran.

Tema yang akan digunakan dalam pembelajaran dikembangkan mengacu pada karakteristik dan kriteria yang ada dengan 
langkah-langkah berikut. (Couglin, 1997; Feneey, et.al, 2006; Kostelnik, 2007; Jackman, 2009).

a. Memilih topik yang akan dijadikan tema. Topik yang akan dipilih sebagai tema haruslah yang sesuai dengan usia dan latar belakang anak, mudah mencari media pendukungnya, dan sudah dipahami oleh pendidik. Pembelajaran tematik fokus pada topik yang harus dibahas secara tuntas, jadi bukan ketuntasan pada bidang studi atau bidang pengembangan. Berikut berbagai topik yang dapat dipilih sebagai tema.

Tabel1. Contoh topik untuk tema

\begin{tabular}{|l|ll|}
\hline Sumber Tema & Topik tema \\
\hline Anak & - & Diri sendiri \\
& - & Sahabat \\
& - & Lingkungan \\
& - & Kebutuhan \\
& - & Tanaman \\
& - & Binatang \\
\hline Kejadian Istimewa & - & dst \\
& - & Hari kemerdekaan \\
& - & Sumpah Pemuda \\
& - & Hari pendidikan \\
\hline Kejadian insidental & - & dst \\
& - & Sukoi \\
& - & Bencana alam \\
& - & Debu \\
& - & Banjir \\
& - & Macet \\
& - & dst \\
\hline Guru \& Orang tua & - & Sekolah \\
& - & Sekaten \\
& - & Tanah Air \\
& - & dst \\
\hline
\end{tabular}

b. Brainstorming tentang tema yang dapat dilakukan dengan teman sejawat maupun bersama anak. Tujuan brainstorming ini agar ada kesepahaman tentang tema yang akan dikembangkan sehingga tidak terjadi kesalahan konsep dalam penyampaiannya. Brainstorming dapat dilakukan menggunakan model KWL, yaitu

1) K untuk Know atau Tahu

Guru berdiskusi dengan anak untuk menggali pengetahuan anak tentang tema, misalnya tentang cambah. Guru dapat menggunakan pertanyaan "apa yang kalian ketahui tentang kecambah ?"

2) W untuk Want to know atau Ingin tahu

Guru menggali pengalaman anak tentang tema. Guru dapat menggunakan pertanyaan "apa yang ingin ketahui tentang kecambah ?"

3) L untuk Learning atau belajar Guru menggali keinginan anak menggunakan pertanyaan "apa yang akan kalian pelajari dari kecambah?"

c. Mencari literatur. Gunakan literatur untuk menambah wawasan tentang tema yang akan dikembangkan pendidik di dalam kelas. Pendidik perlu lebih dahulu mencari wawasan mengenai tema yang akan dikembangkannya. Misalnya, guru perlu mencari tahu apa saja yang bisa menjadi kecambah, bagaimana menanam kecambah, apa manfaat kecambah, dan seterusnya.

d. Mengembangkan tema besar menjadi tema kecil. Kembangkan tema menjadi sub tema. Pengembangan tema menjadi sub tema ini bertujuan untuk membuat topik pembelajaran menjadi lebih rinci agar pembahasan topik menjadi fokus. Berikut contoh pengembangan tema menjadi sub tema.

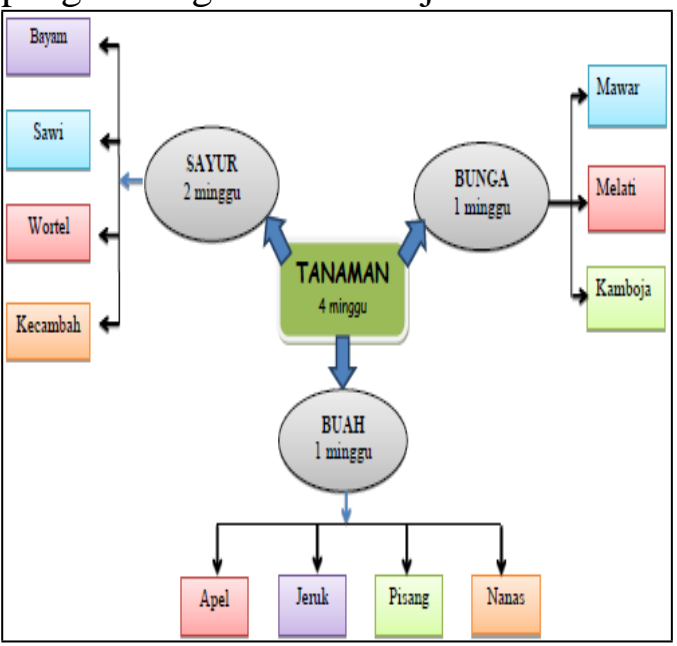

Gambar 1. Contoh Pengembangan Tema menjadi Sub Tema

Sumber : Laporan Workshop PPG Nanik Setiayani, 2017 
e. Menyusun konsep pengetahuan tentang tema kecil yang akan dikembangkan. Penyusunan konsep menggunakan pertanyaan $5 \mathrm{~W}, 1 \mathrm{H}$ sehingga diperoleh pengetahuan tentang topik. Berikut contoh pengembangan konsep pengetahuan tema.

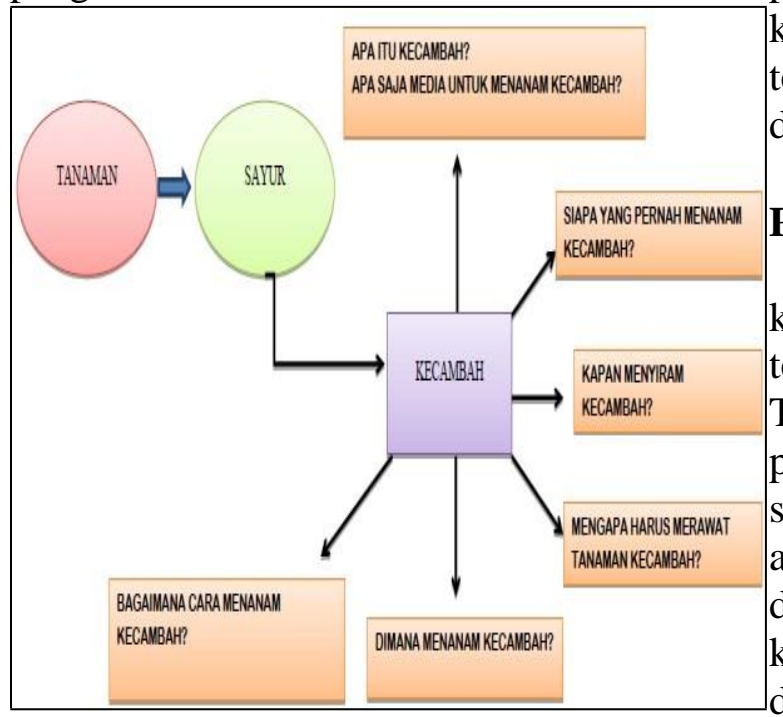

Gambar 2. . Contoh Penyusunan Konsep Pengetahuan Sub Tema (Tema Kecil) Sumber : Laporan Workshop PPG Nanik Setiayani, 2017

f. Menentukan puncak tema. Puncak tema perlu disusun untuk merangkum seluruh pembahasan sub tema yang ada di tema besar itu. Puncak tema merupakan kegiatan yang menyenangkan bagi anak dan mampu mengingatkan kembali terhadap pembahasan yang telah lalu. Contoh puncak tema dari tema kecambah adalah proyek membuat bakwan.

g. Melaksanakan tema dalam pembelajaran. Pelaksanaan tema dalam pembelajaran tidak perlu terlalu kaku, tetapi perlu memperhatikan prinsip keinsidentalan sehingga tema yang digunakan dapat berubah sewaktuwaktu sesuai kebutuhan.

Tahap tindak lanjut pengembangan tema. Tindak lanjut terhadap pengembangan tema yang ada dapat dilakukan setelah tema digunakana dalam pembelajaran. Tindak lanjut yang dilakukan dapt berupa evaluasi pelaksanaan tema yang bertujuan untuk menggali : (1) Ketertarikan anak terhadap tema yang dipilih. Jika anak tidak terlalu berminat, maka tema tersebut dapat diganti untuk tahun-tahun mendatang; (2) Kemudahan guru mencari sumber bacaan dan sumber pembelajaran. Jika guru mengalami kesulitan mencari keduanya, maka tema tersebut belum dapat dikatakan kontekstual dan dapat diganti untuk tahun mendatang.

\section{PENUTUP}

Kurikulum 2013 PAUD memberikan kebesana pada guru untuk mengembangkan tema pembelajarannya di kelas secara unik. Tema mutlak dibutuhkan bagi pembelajaran di TK untuk menyatukan seluruh proses pembelajaran dari kegiatan awal hingga akhir. Tema sebaiknya disesuaikan dengan latar belakang kehidupan anak, sumberdaya yang tersedia, dan perkembangan anak.

Ada tiga langkah besar dalam mengembangkan tema, yaitu persiapan, pelaksanaan, dan tindak lanjut. Langkah persiapan berupa kegiatan menganalisi sumber daya yang dapat dijadikan tema. Tahap pelaksanaan pengembangan tema terdiri dari 7 kegiatan, yaitu memilih topik, brainstorming, mencari literatur, mengembangkan tema jadi sub tema, menyusun konsep pengetahuan dari tema kecil, menentukan puncak tema, dan implementasi tema. Langkah tindak lanjut berisi kegiatan evaluasi pelaksanaan tema.

\section{Bahan Bacaan}

Brewer, J.A. (2007). Introduction to early chlidhood education. USA: Pearson Education, Inc.

Couglin, P. A., et.al. (1997). Creating child-centered classroom 3-5 years olds. Washington: CRI, Inc.

DITJEN PAUDNI. (2014). Pedoman pengembangan tema pembelajaran pendiidkan anak usia dini. Jakarta: Kemendikbud. 
Feeney, S., Christensen. D., Moravcik E. (2006). Who am I in the live of children ?. USA: Pearson MerrillPrentice Hall.

Jackman, H. L. (2009). Early education curriculum. USA: Delmar, Cengage Learning.

Maryatun, I.B. (2017). Laporan penelitian awal "panduan pengembangan tema berbasis budaya Yogyakarta". Yogyakarta: UNY
Montolalu, dkk., Bermain dan Permainan Anak, (Jakarta: Penerbit Universitas Terbuka, 2012).

Nurani, Y. (2013). Konsep Dasar Pendidikan Anak Usia Dini. Jakarta: Indeks.

Setiyani, N. (2017). Laporan Hasil Workshop SSP PPG SM3T. Yogyakarta: Prodi PGPAUD 